Vietnam Journal of Mechanics, VAST, Vol. 27, No. 2 (2005), pp. 96-106

\title{
TWO DIMENSION NUMERICAL MODELING OF WAVE AND WIND INDUCED CURRENTS AND BED MORPHOLOGY EVOLUTION AT PHAN RI - BINH THUAN COASTAL ZONE
}

\author{
Le Xuan Hoan, Pham Thanh Nam \\ Institute of Mechanics
}

\begin{abstract}
Based on the 2DH model for calculating the wave induced currents, established by Christopher G. Koutitas [1], a 2DH numerical model for calculating the wave and wind induced currents (current-model) is developed with taking additional account of shear stress due to wind and eddy viscosity components. A $2 \mathrm{DH}$ numerical model for calculating the sediment transport and bed morphology evolution (sand-model) is developed and linked to the above current- model. The wave parameters used for the input of the models are obtained from the RCPWAVE model. This paper presents some numerical results of calculating the currents induced by wind and waves and bed morphology evolution at Phan Ri - Binh Thuan coastal zone for two typical cases of wind: NE and SW monsoons.
\end{abstract}

\section{INTRODUCTION}

Calculation of the sediment transport and prediction of the bed morphology evolution as well as shoreline evolution are very essential for engineering and sustainable development in littoral economic zones. Sediment transport, bed and shoreline evolution are complex phenomena caused by many hydrodynamic processes in coastal zones such as sea water level changing (tide, typhoon surge...), wave, tidal current, wind-induced current, waveinduced current and river flow. Therefore, calculating the wave and current parameters must be done before calculating the sediment transport, bed and shoreline evolution. The procedures of calculation include:

- Calculating the wave parameters and wave radiation stresses using the RCPWAVE model.

- Calculating the current induced by wind and wave using the current-model.

- Calculating sediment transport and bed morphology evolution using the sand-model.

\section{GOVERNING EQUATIONS}

\subsection{RCPWAVE model}

The "Regional Coastal Processes Numerical Modeling System" (RCPWAVE), which was developed by US Army Corps in 1986, is a modeling system that calculates the linear wave propagation. It is applied in many projects in the world. It considers only refractive and shallow effects. The reflective and diffractive effects are not considered. Thus, this model can be applied well only for light slope bottom zones without breakwater or jetty. [2]:

The mild slope equation can be expressed in the following form (Berkhoff, 1972, 1976)

$$
\frac{\partial}{\partial x}\left(c c_{g} \frac{\partial \phi}{\partial x}\right)+\frac{\partial}{\partial y}\left(c c_{g} \frac{\partial \phi}{\partial y}\right)+\sigma^{2} \frac{c_{g}}{c} \phi=0
$$


where

$c(x, y)=\sigma / k$ - phase velocity $[\mathrm{m} / \mathrm{s}]$,

$\sigma$ - angular wave frequency (defined as $2 \pi / \mathrm{T}$ ) [radian $/ \mathrm{s}$,

$k(x, y)$ - wave number given by the dispersion relation: $\sigma^{2}=g k \tanh (k d)[\mathrm{radian} / \mathrm{m}]$,

$d(x, y)$ - still - water depth $[\mathrm{m}]$.

$T$ - wave period $[1 / \mathrm{s}]$,

$c_{g}(x, y)=\partial \sigma / \partial k-$ group velocity $[\mathrm{m} / \mathrm{s}]$,

$\phi(x, y, t)$ - complex velocity potential,

$x, y$ - horizontal orthogonal coordinates,

$t$ - time $[\mathrm{s}]$,

$g$ - acceleration due to gravity $\left[\mathrm{m} / \mathrm{s}^{2}\right]$.

The velocity potential function for linear, monochromatic, plane wave can be represented by the harmonic expression.

$$
\phi=a e^{i s t}
$$

where $a(x, y)=g H(x, y) / 2 \sigma$ - wave amplitude $[\mathrm{m}]$,

$H(x, y)$ - wave height $[\mathrm{m}]$,

$s(x, y)$ - wave phase [radian].

By substituting the velocity potential function (2.2) into equation (2.1) and separating the real and imaginary parts, two following equations can be derived:

$$
\begin{gathered}
\frac{1}{a}\left\{\frac{\partial^{2} a}{\partial x^{2}}+\frac{\partial^{2} a}{\partial y^{2}}+\frac{1}{c c_{g}}\left[\nabla a \cdot \nabla\left(c c_{g}\right)\right]\right\}+k^{2}-|\nabla s|^{2}=0 \\
\frac{\partial}{\partial x}\left(a^{2} c c_{g}|\nabla s| \cos \theta\right)+\frac{\partial}{\partial y}\left(a^{2} c c_{g}|\nabla s| \sin \theta\right)=0
\end{gathered}
$$

where $\nabla$ - horizontal gradient operation, $\theta(x, y)$ - wave direction [radian].

The output parameters of RCPWAVE model are wave height $H$, wave direction $\theta$ and wave number $k$, that are obtained by solving of the equations (2.3), (2.4) and the dispersion relation [2].

\subsection{Wave and wind induced current model}

The wave and wind induced current model is developed from the $2 \mathrm{DH}$ model for calculating the wave induced currents, established by Christopher G. Koutitas [1], and then this model is improved by additionally taking into account of the shear stress due to wind and the horizontal eddy viscosity components. Besides that, boundary conditions at the lateral boundary are improved by second order extrapolative formula. The governing equations of the model are as follows:

$$
\begin{aligned}
\frac{\partial U}{\partial t}+U \frac{\partial U}{\partial x}+V \frac{\partial U}{\partial y}= & -g \frac{\partial \zeta}{\partial x}+f V+\frac{\tau_{s x}}{\rho h}-\frac{\tau_{b x}}{\rho h}- \\
& -\frac{1}{\rho h}\left(\frac{\partial S_{x x}}{\partial x}+\frac{\partial S_{x y}}{\partial y}\right)+\nu_{h}\left(\frac{\partial^{2} U}{\partial x^{2}}+\frac{\partial^{2} U}{\partial y^{2}}\right)
\end{aligned}
$$




$$
\begin{aligned}
\frac{\partial V}{\partial t}+U \frac{\partial V}{\partial x}+V \frac{\partial V}{\partial y}= & -g \frac{\partial \zeta}{\partial y}-f U+\frac{\tau_{s y}}{\rho h}-\frac{\tau_{b y}}{\rho h}- \\
& -\frac{1}{\rho h}\left(\frac{\partial S_{y y}}{\partial y}+\frac{\partial S_{x y}}{\partial x}\right)+\nu_{h}\left(\frac{\partial^{2} V}{\partial x^{2}}+\frac{\partial^{2} V}{\partial y^{2}}\right) \\
& \frac{\partial \zeta}{\partial t}+\frac{\partial U h}{\partial x}+\frac{\partial V h}{\partial y}=0
\end{aligned}
$$

where $U, V$ - depth mean horizontal velocity components in $x$ and $y$ direction $[\mathrm{m} / \mathrm{s}]$,

$\zeta$ - water elevation [m],

$f=2 \Omega \sin \varphi$ - Coriolis parameter $[1 / \mathrm{s}], \Omega$ is the angular frequency of the earth rotation $\left(=0.73 \times 10^{-4} \mathrm{radian} / \mathrm{s}\right), \varphi$ is the geographic latitude of the calculated domain,

$h=d+\zeta$ - water depth $[\mathrm{m}]$,

$\tau_{s x}, \tau_{s y}$ - components of shear stress at the sea surface $\left[\mathrm{N} / \mathrm{m}^{2}\right]$, expressed by the quadratic forms [1]: $\tau_{s x}=\rho C_{s} W_{x} \sqrt{W_{x}^{2}+W_{y}^{2}}, \tau_{s y}=\rho C_{s} W_{y} \sqrt{W_{x}^{2}+W_{y}^{2}}$,

$W_{x}, W_{y}$ - wind velocity components in $\mathrm{x}$ and $\mathrm{y}$ direction $[\mathrm{m} / \mathrm{s}]$,

$\rho$ - water density $\left[\mathrm{kg} / \mathrm{m}^{3}\right]$,

$C_{s}$ - surface wind friction coefficient,

$\tau_{b x}, \tau_{b y}$ - components of shear stress at the sea bottom $N / m^{2}$, expressed by the quadratic forms [1]: $\tau_{b x}=\rho C_{f} U \sqrt{U^{2}+V^{2}}, \tau_{b y}=\rho C_{f} V \sqrt{U^{2}+V^{2}}$,

$C_{f}$ - bed frictional coefficient,

$S_{x x}, S_{y y}, S_{x y}$ - components of wave radiation stress $\left[\mathrm{N} / \mathrm{m}^{2}\right]$,

$\nu_{h}$ - horizontal eddy viscosity function $\left[\mathrm{m}^{2} / \mathrm{s}\right]$, is determined by following formula [7]: $\nu_{h}=N(d+\zeta) \sqrt{g(d+\zeta)}, N$ is dimensionless parameter.

\section{Initial conditions:}

$$
U=0, \quad V=0, \quad \zeta=0
$$

\section{Boundary conditions:}

- at the solid boundary:

$$
U=0, \quad V=0 .
$$

- at the lateral boundary:

the second order extrapolative formulas are used [3]:

$$
\begin{aligned}
U_{i, j}^{n} & =\frac{1}{3}\left(4 U_{i-1, j}^{n}-U_{i-2, j}^{n}+\left.2 \Delta x \frac{\partial U}{\partial x}\right|_{i, j} ^{n}\right), \\
V_{i, j}^{n} & =\frac{1}{3}\left(4 V_{i, j-1}^{n}-V_{i, j-2}^{n}+\left.2 \Delta y \frac{\partial V}{\partial y}\right|_{i, j} ^{n}\right) .
\end{aligned}
$$


- at the offshore boundary:

the second order extrapolative formula (2.10) is used for along shore velocity component $U$, and radiation condition (2.12) is used for perpendicular shore velocity component $V$ :

$$
V=-\zeta \sqrt{g / h}
$$

Equations (2.5), (2.6) and (2.7) with the initial conditions (2.8) and the boundary conditions (2.9)-(2.12) are solved by an explicit finite different scheme [1].

\subsection{Bed morphology evolution model}

The mathematical relation for predicting evolution of a coastline or the water depth in a coastal area with considerable sediment transport is derived from principle of mass conservation for the moving grains. Defining the total volume discharge (suspended and bed load) of sediment along the $\mathrm{x}$ and $\mathrm{y}$ horizontal directions, by $q_{t x}, q_{t y}$, for a nearly horizontal bed (mild slope assumption), the time rate of change of the bed level $\eta$ is given by [4]:

$$
\frac{\partial \eta}{\partial t}=\frac{1}{1-\varepsilon}\left(\frac{\partial q_{t x}}{\partial x}+\frac{\partial q_{t y}}{\partial y}\right)
$$

where

$\eta$ - bed level, relative to an arbitrary datum $[\mathrm{m}]$,

$\varepsilon$ - porosity coefficient,

$q_{t x}, q_{t y}$ - components of total volumetric sediment transport rate in positive $x, y$ direction $\left[\mathrm{m}^{2} / \mathrm{s}\right]$.

The total load transport by waves plus currents $q_{t}$ is expressed by Soulsby - Van Rijn $[4]:$

$$
q_{t}=A_{s} U\left[\left(U^{2}+\frac{0.018}{C_{D}} U_{r m s}^{2}\right)^{1 / 2}-U_{c r}\right]^{2.4}(1-1.6 \tan \beta)
$$

where

$$
A_{s}=A_{s b}+A_{s s}, \quad A_{s b}=\frac{0.005 h\left(d_{50} / h\right)^{1.2}}{\left[(s-1) g d_{50}\right]^{1.2}}, \quad A_{s s}=\frac{0.012 d_{50} D_{*}^{-0.6}}{\left[(s-1) g d_{50}\right]^{1.2}},
$$

$U$ - depth averaged current velocity $[\mathrm{m} / \mathrm{s}]$,

$U_{m r s}$ - root mean square wave orbital velocity $[\mathrm{m} / \mathrm{s}]$,

$$
U_{r m s}=\frac{\pi H_{s}}{T_{n} \sinh (k h)}
$$

$H_{s}$ - significant wave height $[\mathrm{m}]$,

$T_{n}=(h / g)^{1 / 2}$ - scaling period of water wave [s],

$C_{D}=\left[\frac{0.40}{\ln \left(h / z_{0}\right)-1}\right]^{2}$ - drag coefficient due to current alone,

$U_{c r}$ - threshold current velocity, determined by the formula of Van Rijn [4]:

$U_{c r}=0.19\left(d_{50}\right)^{0.1} \log _{10}\left(4 h / d_{90}\right)$ for $100 \leq d_{50} \leq 500 \mu \mathrm{m}$,

$U_{c r}=8.5\left(d_{50}\right)^{0.6} \log _{10}\left(4 h / d_{90}\right)$ for $500 \leq d_{50} \leq 2000 \mu \mathrm{m}$, 
$\beta$ - slope of bed in streamwise direction, positive if flow runs uphill,

$d_{50}$ - median grain diameter $[\mathrm{m}]$,

$z_{0}$ - bed roughness length,

$s=\rho_{s} / \rho_{w}$ - relative density of sediment,

$\nu$ - kinematic viscosity of water $\left[\mathrm{m}^{2} / \mathrm{s}\right]$,

$D^{*}$ - dimensionless grain size, $D_{*}=\left[\frac{g(s-1)}{\nu^{2}}\right]^{1 / 3} d_{50}$.

Discretizing equation (2.12), we have the finite difference equation that expresses the bed morphology evolution:

$$
\eta_{i j}^{n}=\eta_{i j}^{n-1}+\frac{1}{1-\varepsilon} \Delta t\left[\left(\frac{\left.q_{t x}\right|_{i+1, j} ^{n}-\left.q_{t x}\right|_{i-1, j} ^{n}}{2 \Delta x}\right)+\left(\frac{\left.q_{t y}\right|_{i, j+1} ^{n}-\left.q_{t y}\right|_{i, j-1} ^{n}}{2 \Delta y}\right)\right]
$$

\section{NUMERICAL EXPERIMENTS}

\subsection{Calculation of the wave parameters}

The wave propagation model RCPWAVE has been validated toward field data in several previous studies. For example, the two dimension numerical model for wave induced currents in the same coastal zone was investigated by Le Xuan Hoan and Nguyen Manh Hung (2003) [5].

Two test cases corresponding to two prevailing monsoons of $N E$ and $S W$ are taken. For $N E$ monsoon, the wave parameters at offshore boundary are given as follows: wave height $H=1.9 \mathrm{~m}$, wave period $T=7.5 \mathrm{~s}$, wave direction $\theta=22.5 \mathrm{deg}(E N E)$. For $S W$ monsoon: wave height $H=2.0 \mathrm{~m}$, wave period $T=7.6 \mathrm{~s}$, wave direction $\theta=-67.5 \operatorname{deg}$ (SSE) [6]. The obtained results are presented in Fig. 1 and Fig. 2.

\subsection{Calculation of the current parameters}

The waves and wind induced current model has been calibrated and verified by adjusting the surface wind friction coefficient $C_{s}$, the bed friction coefficient $C_{f}$, and dimensionless parameter $N$, so that the best agreement between computed and measured values is obtained. These coefficients have values depending on the wind, flow, fluid and bed morphology. An approximation to their orders of magnitude is $[1] \mathrm{O}\left[\mathrm{C}_{s}\right]=10^{-6}, \mathrm{O}\left[C_{f}\right]$ $=10^{-2}, \mathrm{O}[N]=0 \div 0.016$. After the calibration step, the coefficients obtained are: $C_{s}=$ $0.000001, C_{f}=0.01$ and $N=0.016$.

A good agreement between the computed and measured values is also obtained for the verification step (Table 1. and Fig. 3) with the maximum relative error of about $20 \%$. An relative error within $10 \%$ is accepted for the prediction of tidal level. However, the prediction of marine currents is much more difficult than that of tidal level. Therefore, at the present time, an critical value of relative error for predicting the marine currents has not been established. Under the existing situation of computational technology, the maximum relative error of about $20 \%$ for the prediction of marine currents is acceptable.

The computed velocity fields induced by wind and wave, corresponding to two typical cases of monsoon are shown in Fig. 4 and Fig. 5. The dominant direction of the velocity field in the $N E$ monsoon is the southward and the inverse direction in the $S W$ monsoon. 
The maximum of current velocity is about $0.7 \mathrm{~m} / \mathrm{s}$ at the South of the computed region and the strip of large velocity occurs in the surf zone.

\subsection{Calculation of the bed morphology evolution}

The input parameters for calculating sediment transport and bed evolution are given as follows [6]: $d_{50}=300 \mu \mathrm{m} ; d_{90}=500 \mu \mathrm{m} ; \rho_{w}=1025 \mathrm{~kg} / \mathrm{m}^{3} ; \rho_{s}=2650 \mathrm{~kg} / \mathrm{m}^{3} ; \nu=0.9 \times$ $10^{-6} \mathrm{~m}^{2} / \mathrm{s} ; z_{0}=0.006 \mathrm{~m} ; \varepsilon=0.3$.

The results of total load transport conresponding to two cases of monsoons are presented in Fig. 6. It shows that the value of total load transport along shore in the $S W$ monsoon is greater than that in the $N E$ monsoon. The reason might be the direction of coastline. Because the shoreline direction is in the $N E-S W$ direction so the angle between breaking wave direction and shoreline in the $S W$ monsoon is greater than that in the $N E$ moonson, and therefore, the influence of wave process on the sediment transport in $S W$ monsoon is more prominent. The averaged total load of longshore sediment transport rates in the $S W$ and $N E$ monsoons are $0.024 \mathrm{~m}^{3} / \mathrm{s}$ and $0.014 \mathrm{~m}^{3} / \mathrm{s}$, respectively. The maximum transport rate occurs at the South of the studied region, that caused by an increase of current velocity there.

The obtained results of bed morphology evolution are presented in Fig. 7 and Fig. 8. In the $N E$ monsoon, the accretion is dominant in the whole studied area with the maximum rate is about $25 \mathrm{~cm} / 30$ hours. However, the erosion is dominant in the whole studied area in $S W$ monsoon, at the maximum rate of $30 \mathrm{~cm} / 30$ hours.

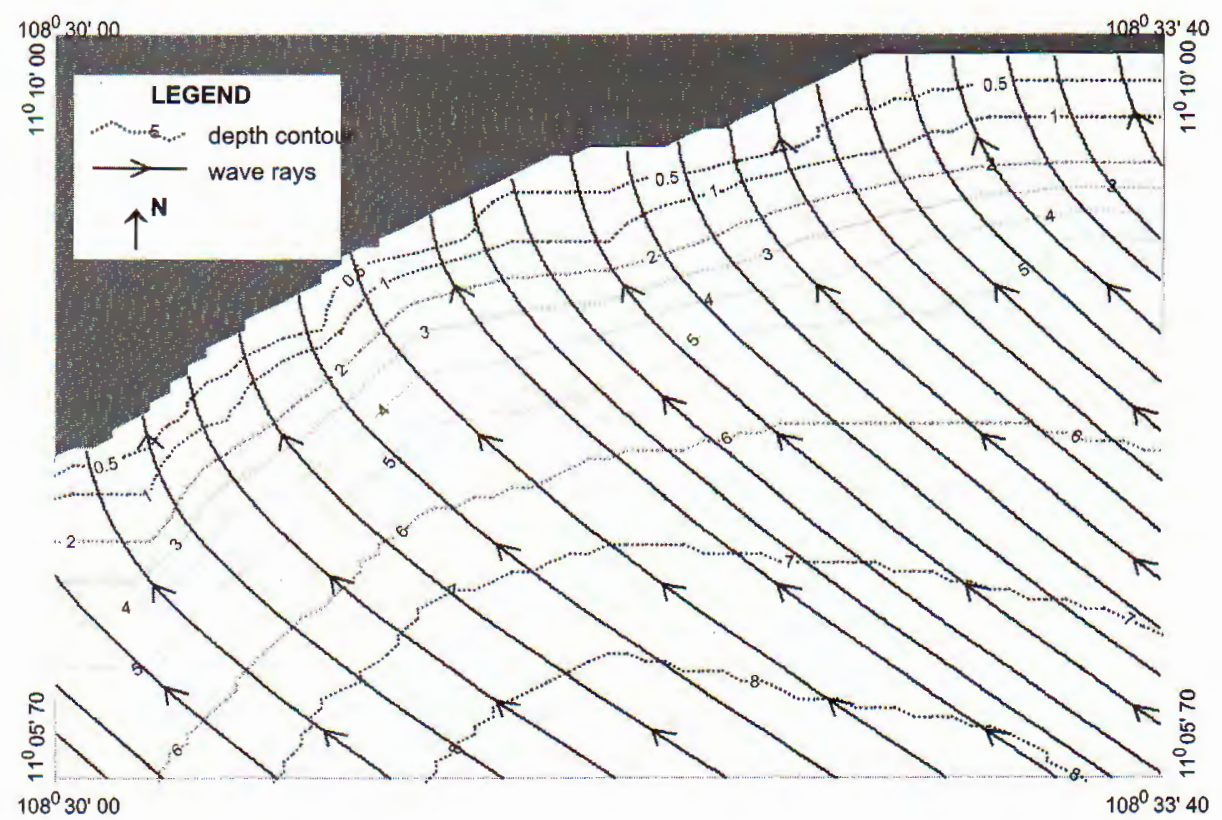

Fig. 1. A wave refraction pattern at Phan $\mathrm{Ri}(T=7.0 \mathrm{~s}, H=2.0 \mathrm{~m}$, ENE direction) 


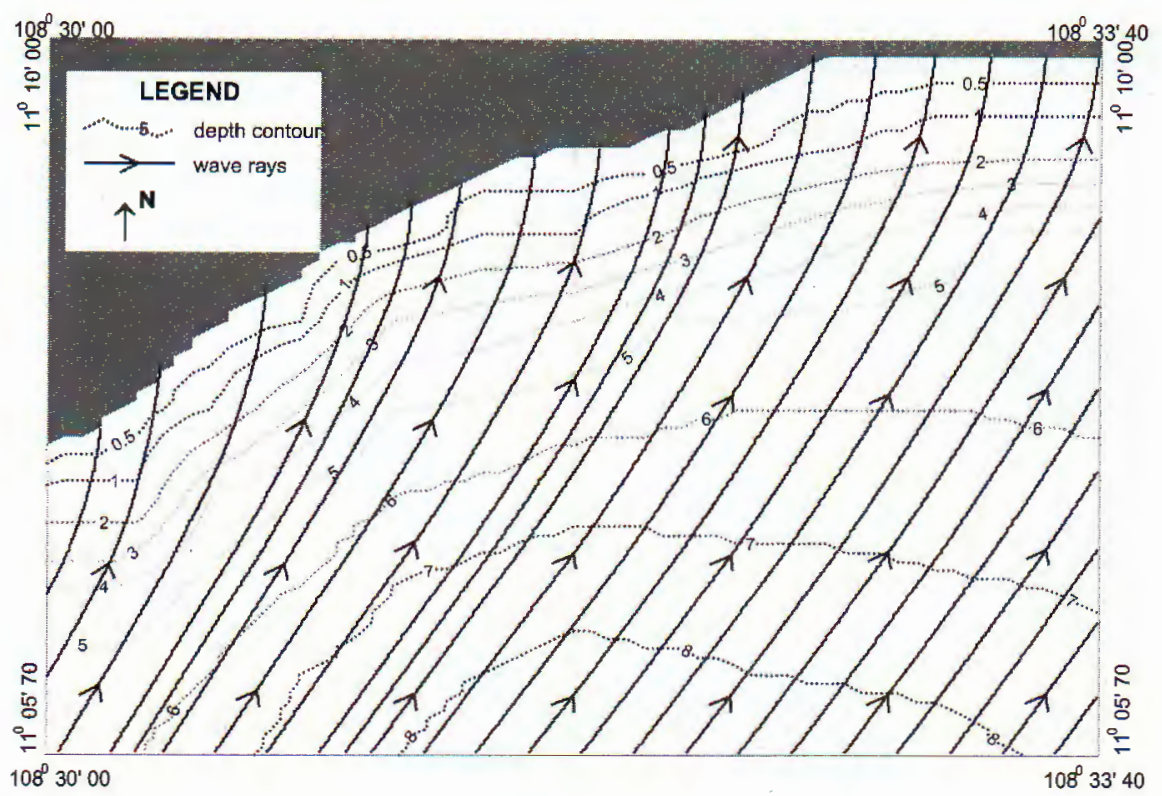

Fig. 2. A wave refraction pattern at $\mathrm{Phan} \mathrm{Ri}(T=7.0 \mathrm{~s}, H=2.0 \mathrm{~m}$, SSE direction)

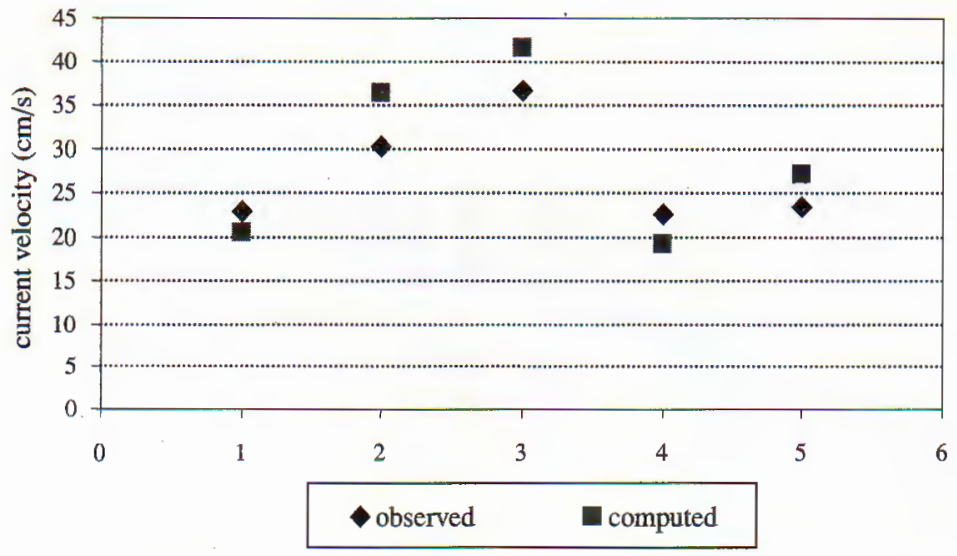

Fig. 3. The comparison between the computed and observed data of wave-wind induced currents

Table. 1. The comparison between the computed and observed values of wave-wind induced currents at the nearshore station

\begin{tabular}{|c|c|c|c|c|c|c|}
\hline \multirow[b]{2}{*}{ Cases } & \multicolumn{3}{|c|}{ The input deep wave parameters } & \multirow{2}{*}{$\begin{array}{c}\text { Observed } \\
\text { current velocity } \\
(\mathrm{cm} / \mathrm{s})\end{array}$} & \multirow{2}{*}{$\begin{array}{c}\text { Computed } \\
\text { current velocity } \\
(\mathrm{cm} / \mathrm{s})\end{array}$} & \multirow{2}{*}{$\begin{array}{c}\text { Error } \\
(\%)\end{array}$} \\
\hline & $\begin{array}{l}\text { wave height } \\
\text { (m) }\end{array}$ & $\begin{array}{l}\text { wave period } \\
\text { (s) }\end{array}$ & $\begin{array}{c}\text { wave } \\
\text { direction }\end{array}$ & & & \\
\hline 1 & 1.3 & 5.6 & SSE & 22.8 & 20.5 & 10.1 \\
\hline 2 & 1.7 & 6.5 & SSE & 30.3 & 36.2 & 19.5 \\
\hline 3 & 1.9 & 5.9 & SSE & 36.7 & 41.5 & 13.1 \\
\hline 4 & 1.2 & 5.9 & SSE & 22.6 & 19.3 & 14.6 \\
\hline 5 & 1.4 & 5.5 & SSE & 23.4 & 27.1 & 15.8 \\
\hline
\end{tabular}




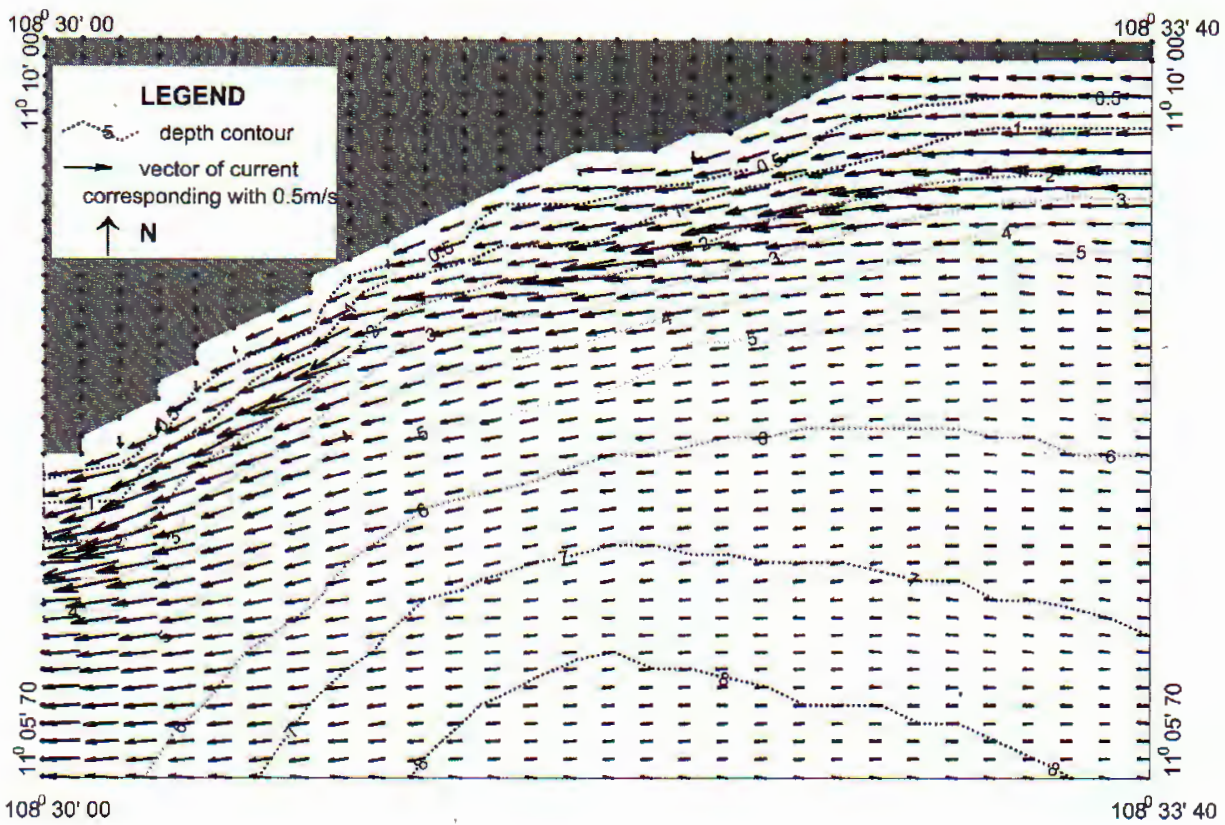

Fig. 4. Distribution of wave-wind induced current at Phan Ri

(wave direction in ENE wind)

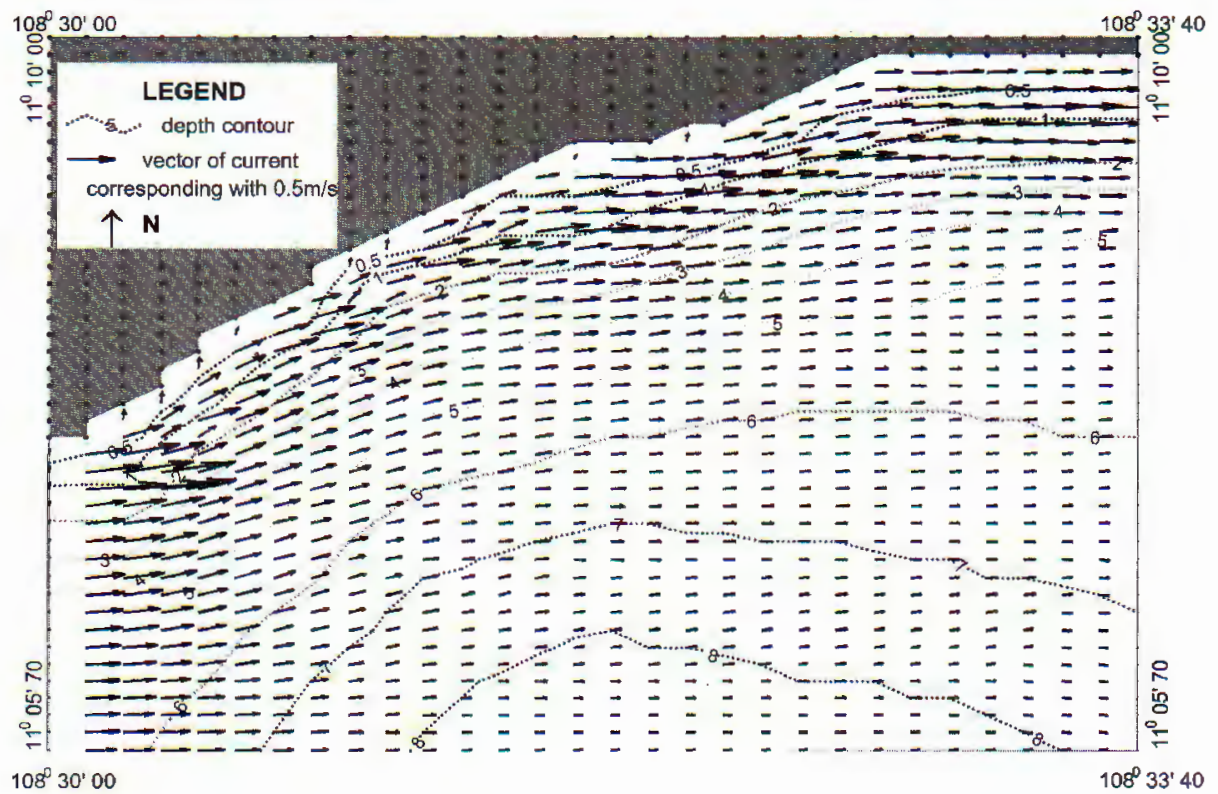

Fig. 5. Distribution of wave-wind induced current at Phan Ri

(wave direction in SSE wind) 


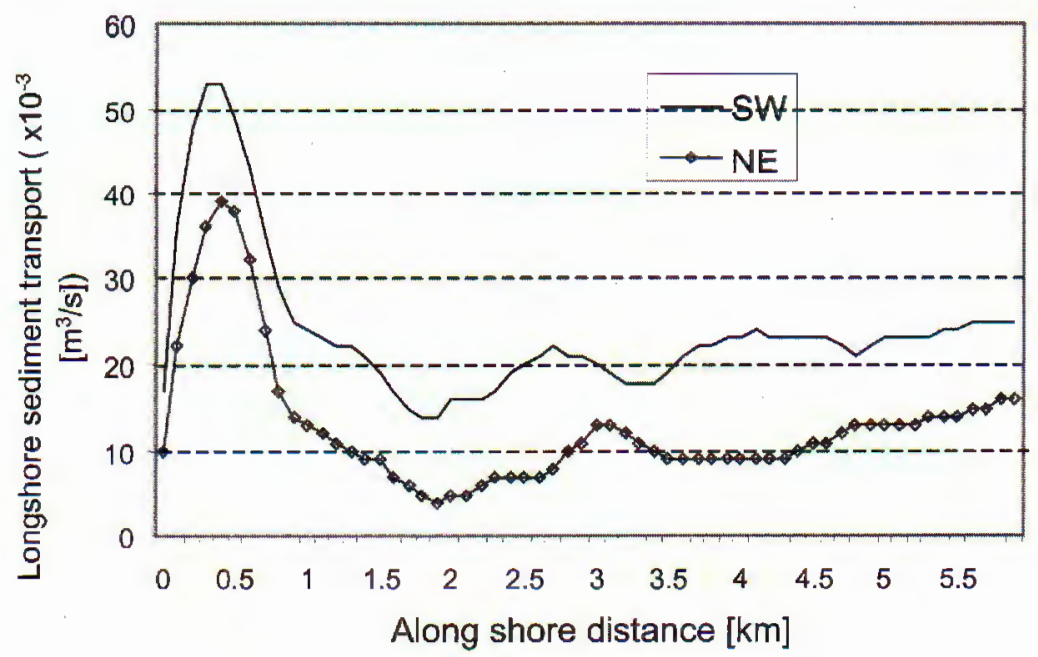

Fig. 6. Distribution of total load transport along shoreline at Phan Ri

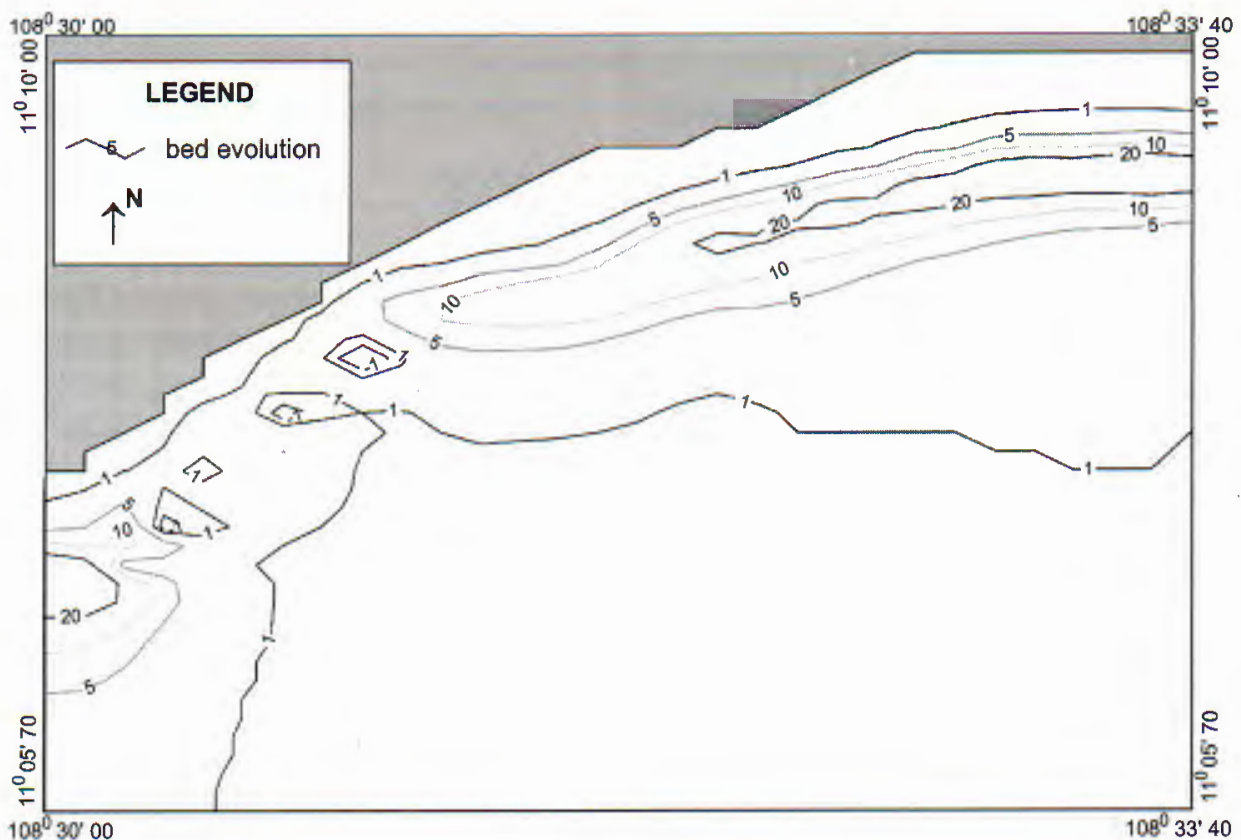

Fig. 7. Contours of bed evolution (cm) after 30 hours at Phan Ri (wave direction in ENE wind) positive numbers: deposition, negative numbers: erosion 


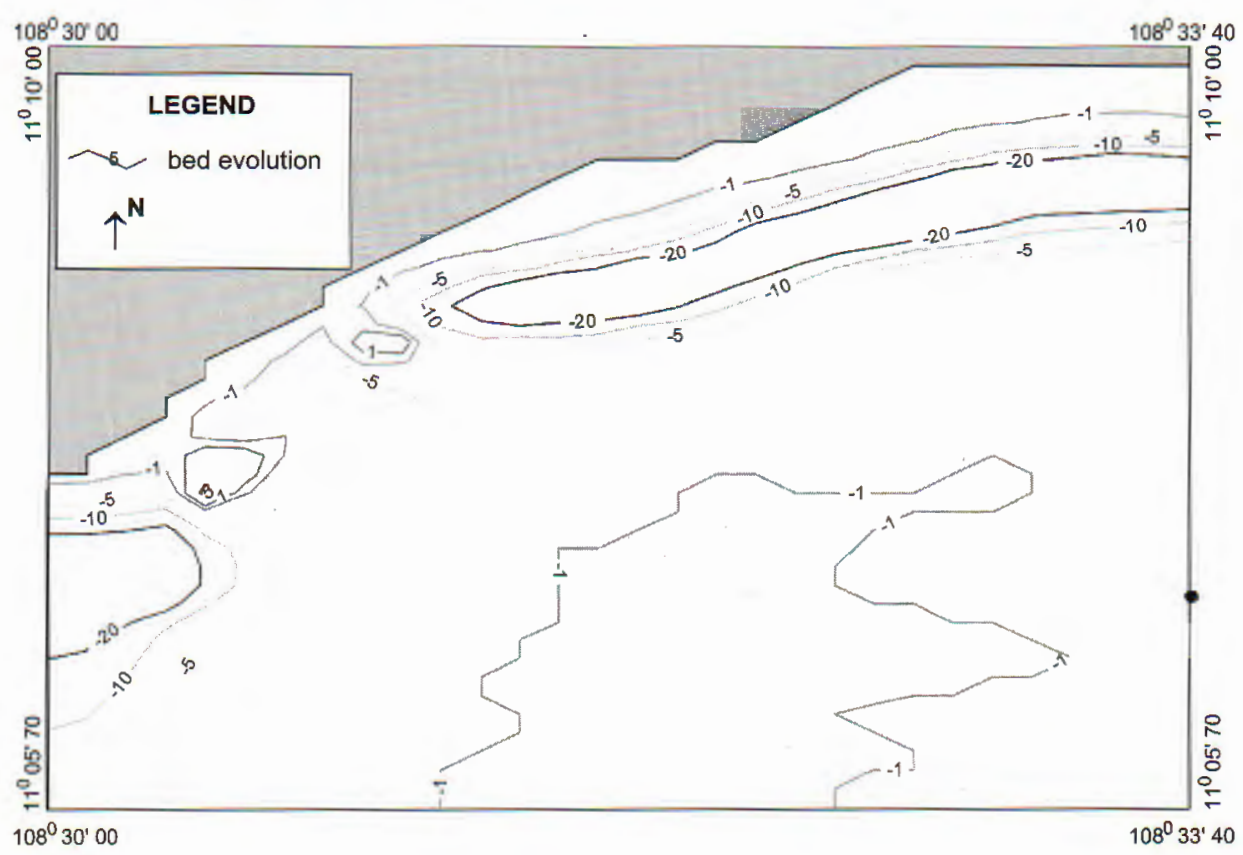

Fig. 8. Contours of bed evolution (cm) after 30 hours at Phan Ri

(wave direction in SSE)

positive numbers: deposition, negative numbers: erosion

\section{CONCLUSIONS}

The wave and wind induced current model has been calibrated and verified by using the measured data. An acceptable agreement between the computed and measured values is obtained. However, this model needs testing more, then it can be applied in practice. The sediment transport and bed morphology evolution model has not been calibrated and verified, because observed sediment transport data are not available. Therefore, the computed values of the sediment transport and bed morphology evolution show only qualitative agreement with reality of the studied area, as follows:

- The total load of longshore sediment transport generated by the wave in the $S W$ monsoon is greater than that in the NE monsoon.

- The wave field of the $N E$ monsoon generates the longshore sediment transport in the southward direction and accreted bed. The wave field of the $S W$ monsoon generates the longshore sediment transport in northward direction and eroded bed.

The authors acknowledge Prof. Pham Van Ninh and Dr. Phan Ngoc Vinh for their useful comments.

The paper were partly supported by fundamental research project "Numerical Simulation on Sediment Transport, No, 321601". 


\section{REFERENCES}

1. Christopher G. Koutitas, Mathematical Models in Coastal Engineering, Pentech Press, London, 1988.

2. Bruce A. Ebersole, Mary A. Cialone, Mark D. Prater, RCPWAVE - a Linear Wave Propagation Mode for Engineering Use, Department of the Army US Army Corps of Engineers, Washington, DC 20314-1000, 1986

3. Dang Huu Chung, Mathematical Numerical Methods for Mechanics, Institute of Mechanics, Ha noi, 2001.

4. Richard Soulsby, Dynamics of Marine Sands, Thomas Telford, Oxford, 1997.

5. Le Xuan Hoan, Nguyen Manh Hung, A two dimension numerical model for waves induced currents in the coastal zone, Vietnam Journal of Mechanics 24 (2003).

6. Nguyen Van Moi, Le Hong Van, A report of observed and data analysing results at the Phan Ri - Binh Thuan zone, The Sumerized Report of National Research Project, KHCN-06.10, Department of Marine Mechanics, Institute of Mechanics, Hanoi, 1999 - 2000.

Received March 31, 2005 Revised April 27, 2005

\section{MÔ PHÒNG HAI CHIỀU DÒNG CHẢY DO SÓNG, GIÓ VÀ BIẾN ĐỔI ĐÁY TẠI VÙNG BIỂN PHAN RÍ - BÌNH THUẬN}

Một mô hình 2D tính dòng chảy do sóng và gió được xây dựng dựa trên mô hình $2 \mathrm{D}$ tính dòng chảy do sóng của Christopher $\mathrm{G}$. Koutitas bằng cách đưa vào thành phần ứng suất do gió và hệ số rối ngang. Một mô hình $2 \mathrm{D}$ tính dòng vận chuyển bùn cát và biến đổi đáy được xây dụng và kết nối với mô hình tính dòng chảy ở trên. Các tham số sóng sứ dụng cho các mô hình này nhận được từ mô hình tính sóng RCPWAVE. Bài báo trình bày một số kết quả áp dụng các mô hình trên để tính dòng cháy do sóng, gió và biến đổi đáy ứng với hai trường sóng đặc trưng trong hai mùa gió Đông Bắc và Tây Nam tại vùng biển Phan Rí - Bình Thuận. 